\title{
Off-label Prescription and Challenges in Clinical Practice: An Abridged Review
}

\author{
Deepika Tikoo ${ }^{1}$, Meenakshi Gupta ${ }^{2}$
}

\begin{abstract}
Off-label use of drugs means the use of drugs for indications, dose, dosage forms, route, and patient population for which approval from the regulatory bodies like US Food and Drug Administration (US FDA) and Drugs Controller General of India (DCGI) has not been obtained. It does not mean that it is illegal or contraindicated to use the drug as off-label. The purpose of off-label prescribing is to provide the maximum benefit to the patients, especially the vulnerable population like pediatric, psychiatric, pregnant, and cancer patients where there is not sufficient data available for the drug use or in diseases where no treatment is yet available. Hence, valid scientific data and an expert opinion can be relied upon for off-label use. There still remains concerns for safety when prescribing for off-label purpose due to the lack of adequate safety and efficacy studies, and thus a physician must assess the risk/benefit ratio before its use. The regulatory bodies like US FDA has formulated certain guidelines for off-label use while the DCGI still does not support its use. Hence, there is no uniformity in the rules and regulations about off-label prescribing around the world, which needs to be streamlined.

Keywords: Off-label drugs, Prescribing, Stake holders.

AMEl's Current Trends in Diagnosis \& Treatment (2020): 10.5005/jp-journals-10055-0098
\end{abstract}

\section{INTRODUCTION}

\section{Background}

Off-label drug prescribing is a common phenomenon all over the world with its usage being as high as $91 \%$ in pediatric population and $41 \%$ in adults. ${ }^{1}$ Off-label use of drugs refers to the use of an approved medication for an indication, formulation, route, patient population, and dose for which regulatory approval has not been sought. ${ }^{1,2}$ As no uniform international guidelines are available for off-label drug use, it becomes the responsibility of the national regulatory agencies to ensure that there is presence of substantial scientific data and evidence of potential benefit of the drug and that the patient has been well informed about its status plus the risk management strategies are in place in case of an adverse effect.

\section{Current Status}

Off-label drugs are widely used in clinical practice, especially in psychiatry, oncology, and pediatrics. As very few clinical trials are carried out in these special population groups, the data for the approved drug indication, route, and dose are not available. ${ }^{3-7}$ Henceforth, it becomes the treating physician's decision whether or not to use the off-label drugs in these groups making sure that there is maximum beneficence and no harm to the recipient.

Regulatory bodies worldwide are responsible for approving drugs whether it is for a particular indication or a different dosage, route, or a patient group. As it becomes difficult to seek approval for multiple indications/dose/route of a drug and as it costs a lot of time and money, off-label use hence has become a common practice in many countries. ${ }^{3}$ In USA for example, these drugs are prescribed commonly, do not require approval, and are a physician's responsibility. The agencies in Europe and Japan are also supportive and liberal about off-label drug use. Regulatory bodies in Australia allow the off-label use provided there is good quality evidence supporting it. In India, however, DCGI does not

\footnotetext{
1,2Department of Pharmacology, Sri Guru Ram Das Institute of Medical Sciences and Research, Amritsar, Punjab, India

Corresponding Author: Deepika Tikoo, Department of Pharmacology, Sri Guru Ram Das Institute of Medical Sciences and Research, Amritsar, Punjab, India, Phone: +91 9501777221, e-mail: dtikoo@gmail.com

How to cite this article: Tikoo D, Gupta M. Off-label Prescription and Challenges in Clinical Practice: An Abridged Review. AMEl's Curr Trends Diagn Treat 2020;4(2):87-90.

Source of support: Nil

Conflict of interest: None
}

allow for off-label prescribing and a doctor found guilty of this can face legal implications. ${ }^{1,8,9}$

\section{Aim and Objective}

It is a fact that many healthcare practitioners are prescribing offlabel drugs without sound evidence and lack of awareness, which henceforth leads to an increase in patient morbidity and mortality. Our aim in this brief review is to highlight and provide information about their usage and discuss the ethical dilemmas related to it.

The methodology of literature search includes a review of various electronic articles on PubMed and Google Scholar by using key/text words and medical subject headings (MeSH) and then identifying the references of the retrieved articles on off-label prescription.

\section{Viewpoints about Off-label Prescribing}

Off-label drugs are like a double-edged sword which on the one hand can provide patients with access to new treatment options; on the other hand, the lack of complete knowledge about their use may pose a threat to the patient's safety and lead to undesirable 
outcomes. The aim of any healthcare system is to provide the best therapeutic options to its patients, which brings them maximum benefit but in many situations, these options may not come with a stamp of approval by the authorities. But this does not imply that off-label is an illegal, contraindicated, or an investigational use of a drug. It should be evidence based and when standard or approved therapies have failed or are not available.

The three important stakeholders involved in the off-label use are the doctor, the patient, and the regulatory agency and it would be worthwhile to mention their viewpoints and role while weighing the favorable and unfavorable aspects in each. ${ }^{10-12}$

\section{Doctor's Viewpoint}

A doctor has the responsibility of doing what is in the best interest of his/her patient. Many countries give their physicians the liberty to decide if off-label use in patients is justified or not. With rapid advances in medical science and novel therapies emerging every year, getting approvals for each and every molecule/indication/ dosage/route by the pharmaceutical companies is difficult. Hence, drug information literature by drug companies, opinion provided by the recognized authorities, and data published in reputed journals become the key source of scientific data for the practitioners to draw their therapeutic decisions about off-label prescribing. ${ }^{13,14}$

Some well-known examples of off-label drugs used in medical practice have been put forward (Table 1). ${ }^{15-20}$ Beta blocker propranolol originally approved for the treatment of cardiac arrhythmia showed a lot of potential for managing hypertension and heart failure and later got approved for those indications as well. Its prophylactic use in migraine started as an off-label use and now has been given the green signal by the authorities for it. ${ }^{10}$ However, it still finds its use in performance anxiety as an off-label therapy.

Use of aspirin in diabetes for prevention of cardiovascular disease, gabapentin for diabetic neuropathy, bevacizumab for retinal diseases, thalidomide for erythema nodosum leprosum (now has the approval) are other examples of off-label uses., ${ }^{1,10}$

Currently, the coronavirus disease (COVID-19) infection with the novel and life-threatening coronavirus for which no standard therapies are available has also led to the use of off-label medications around the world. Drugs like hydroxychloroquine, lopinavir, ritonavir, remdesivir, and favipiravir have found their way into its management. Scarcity of data about the novel virus, its presentation in different population groups, and it becoming a pandemic in a short span of time and life threatening have all led to rapid decisions about its management strategies. Some of these pharmacotherapy studies previously for Middle East respiratory syndrome CoV (MERS-CoV) have laid the ground for use of these drugs in COVID-19 as the viruses are genetically related. Scientific research is still undergoing to find the best possible treatment option to combat the deadly virus infection. ${ }^{21,22}$

As mentioned earlier, there is no denying the fact that off-label drugs can expose the patient to some unknown risks or ineffective therapy due to lack of complete efficacy and safety studies., ${ }^{7,8}$ The classic examples of such events are use of fenfluramine and phentermine which were approved for short-term use in obesity but their unrestricted long-term combination by the physicians led to fatal cardiac diseases. Another drug quetiapine was prescribed off-label for dementia with agitation while ignoring the warning, that it could increase the death risk in elderly. 1,14,23

Table 1: Drugs/groups with approved and off-label use

\begin{tabular}{|c|c|c|}
\hline Drug name/group & Approved use & Off-label use/uses \\
\hline Albuterol & Asthma & Bad cough \\
\hline Aripiprazole & Antipsychotic & Dementia, Alzheimer's disease \\
\hline Antianxiety drugs & Anxiety disorders & Sleep aid \\
\hline Bumetanide & Diuretic & $\begin{array}{l}\text { Neonatal seizures, temporal lobe seizures, autism, } \\
\text { schizophrenia }\end{array}$ \\
\hline Clonidine & Hypertension & ADHD \\
\hline Gabapentin & Antiepileptic, postherpetic neuralgia & Depression, nerve pain, migraine \\
\hline Ivabradine & Angina, heart failure & $\begin{array}{l}\text { Inappropriate sinus tachycardia, postural orthostatic } \\
\text { hypotension, atrial fibrillation, coronary angiography }\end{array}$ \\
\hline Modafinil & Excessive sleepiness & Enhance wakefulness and alertness \\
\hline Minoxidil & Androgenetic alopecia & $\begin{array}{l}\text { Telogen effluvium, alopecia areata, eyebrow hypotrichosis, } \\
\text { chemotherapy-induced alopecia, Monilethrix }\end{array}$ \\
\hline Naltrexone & Alcohol and opioid dependence & $\begin{array}{l}\text { Kleptomania, compulsive gambling, trichotillomania } \\
\text { (compulsive hair pulling) }\end{array}$ \\
\hline Propranolol & Hypertension, prophylaxis of angina, migraine & Performance anxiety \\
\hline Prazosin & Hypertension & Nightmares due to post-traumatic stress disorder \\
\hline Risperidone & Antipsychotic & Dementia, Alzheimer's disease, eating disorder \\
\hline Trazodone & Antidepressant & Sleep aid, insomnia \\
\hline Tricyclic antidepressants & Antidepressant & Neuropathic pain, chronic pain \\
\hline Tiagabine & Antiepileptic & Depression, mood stability \\
\hline Topiramate & Antiepileptic & Migraine, bipolar disorder, depression, nerve pain \\
\hline
\end{tabular}

$\mathrm{ADHD}$, attention deficit hyperactivity disorder) 


\section{Patient's Viewpoint}

Patients suffering from complex clinical conditions which are not responding to the current standard regimen or for whom there is no existing therapy available are prescribed off-label drugs as new or the only treatment options for the ailment. This seems justifiable if the decision is backed by valid scientific data providing the maximum benefit to the patient which outweighs its harm. ${ }^{4}$ Also, the doctors are ethically required to disclose about off-label drug use to their patients and its risk/benefit ratio and obtain their or the caregiver's consent. This preserves the patient's autonomy and the ethical principles of beneficence and non-maleficence will be fulfilled.

Such transparency and dynamics in a doctor-patient relationship by practice of shared decision-making will strengthen the belief of the patient in his/her physician or else the patient may lose faith in their treating doctor. ${ }^{23-25}$

\section{Regulatory Body's Viewpoint}

There is no uniformity/harmony in the regulations and guidelines for off-label use; hence, the decision for their use is left to the experts (doctors). Also, there is a rising demand for quick access to novel therapies but insufficient availability of safety and efficacy data in a short span of time is a huge challenge for the authorities who cannot decide anything in haste. If they tighten the rein, then many patients might be deprived of different treatment options and if they become lenient, it might lead to misuse and harm to the patient. Every nation has its own regulations, which can be as liberal as in Japan or as stringent as in India.

The European regulatory agencies itself support clinical trials of off-label drugs for certain groups like pediatrics, while France, do not allow the propagation of information about the off-label use. In USA, before 1997, it was illegal for the drug companies to market the off-label uses of the manufactured drug and the drug company Pfizer was fined millions of dollars for marketing gabapentin (Neurontin) for various off-label uses. New guidance issued by the US FDA in 2009 about the promotion of off-label use of drugs is known as "Good Reprint Practices," which provides provisions under which the drug companies may distribute the article copies and valid scientific data about the off-label indications of the drug. ${ }^{4}$ The manufacturer though needed to submit a copy of the materials to the regulatory bodies and seek approval for the new indications. ${ }^{26,27}$

In India, DCGI does not have any clear-cut guidelines on the off-label use of drugs. Indian law presently does not allow the drugs to be prescribed for conditions which have not got the approval (off-label). ${ }^{28}$ Indian medical association, however, is more tolerant toward off-label drug use and has left it to the decision of the physician but it should be backed by relevant scientific data. ${ }^{29}$

\section{Discussion}

The ideal situation about off-label prescription would be that there is a presence of considerable literature backing its use in that indication which suggests maximum benefit and least harm, and the consent for the same has to be taken from the patient or the caregiver.

Absence of clinical trials of drugs in children and psychiatric patients has led to maximum use of off-label prescription in these groups as the scientific data for such use is not always substantial.
Similar scenario can be seen in patients with terminal illness or rare/ novel disease for which no licensed product is yet available. ${ }^{30,31,32}$

The dilemma remains whether to discourage the use of such therapy due to the lack of sufficient efficacy and safety data or to let the expert decide based on his/her judgment and clinical acumen. It seems best that as there is no black or white zone in this case and hence a middle path should be taken by regulating its use and allowing the drug manufacturers to dissipate more information to the regulatory bodies as well as the practitioners so that more transparent clinical decisions can be made. It is especially of more importance in developing countries like ours where the majority of doctors lack information about off-label drugs and use them even in the presence of licensed counterparts.

Also, it must be emphasized that such therapy must never be given to a patient without discussing it with him/her or the caregiver. Patient's autonomy must be respected and the decision for the use of off-label drugs must be arrived at mutually. This builds up the doctor-patient trust and will avoid any ethical discrepancies later.

It will not be unreasonable to say that amongst all this, a strict check on practices of drug manufacturers should be there so that they do not use any unfair/unlawful means to promote their products. The role of regulatory bodies here is very important to streamline the proper promotion and hence avoiding dangerous prescribing practices for the best interest of the patient.

\section{ConCLUSION}

The use of off-label drugs if backed with scientific evidence can be of immense benefit to different patient groups as seeking approval for each and every indication of a drug is difficult due to the cumbersome process of approval. But on the other hand, we cannot ignore the fact that a patient can be exposed to the risk due to lack of documented data. Hence, it becomes crucial to strike a balance and do what is in the best interest of the patient. An honest, dedicated, and focused approach by doctors, drug manufacturers, and the regulatory authorities together can only ensure that.

Also, the patient should feel free to ask about the approved or unapproved indications of the treatment prescribed to him/her and the doctor should lay down the facts in front of the patient as this builds up the trust and faith in a doctor-patient relationship. The regulatory agencies have a huge responsibility to monitor the legitimate use of drugs for off-label purpose based on the risk/ benefit ratio and therefore formulate or streamline guidelines for their use in public.

\section{References}

1. Oberoi SS. Regulating off-label drug use in India: the arena for concern. Perspect Clin Res 2015 Jul-Sep;6(3):129-133. DOI: 10.4103/2229-3485.159935.

2. Khamar B. Off-label use of medicines: medical research and medical practice. Indian J Ophthalmol 2007;55(6):411-412. DOI: 10.4103/03014738.36472.

3. Lücke C, Gschossmann JM, Grömer TW, et al. Off-label prescription of psychiatric drugs by non psychiatrist physicians in three general hospitals in Germany. Ann Gen Psychiatry 2018 Feb;17:1-7. DOI: 10.1186/s12991-018-0176-4.

4. Shakeel S, Iffat W, Nesar S, et al. Exploratory findings of prescribing unlicensed and of label medicines among children and neonates. Integr Pharm Res Pract 2020;9:33-39. DOI: 10.2147/IPRP.S231134. 
5. Mukattash TL, Alzoubi KH, Abuirjie AM, et al. Perceptions and attitudes towards off-label dispensing for pediatric patients, a study of hospital based pharmacists in Jordan. Saudi Pharm J 2018 Jan;26(1):20-24. DOI: 10.1016/j.jsps.2017.11.004.

6. McIntyre J, Conroy S, Avery A, et al. Unlicensed and off label prescribing of drugs in general practice. Arch Dis Child 2000;83(6):498-501. DOI: 10.1136/adc.83.6.498.

7. Sophie H, McNair DS, Birkett NJ, et al. Off-label use of cancer therapies in women diagnosed with breast cancer in the United States. SpringerPlus 2015 May;4:209. DOI: 10.1186/s40064-015-0981-z.

8. Shimazawa R, Ikeda M. Japanese regulatory system for approval of off-label drug use: evaluation of safety and effectiveness in literaturebased applications. Clin Ther 2012;34(10):2104-2116. DOI: 10.1016/j. clinthera.2012.09.004.

9. Council of Australian Therapeutic Advisory Groups (CATAG). Rethinking medicines decision-making in Australian Hospitals: Guiding principles for the quality of off-label medicines. http://www.catag. org.au/wpcontent/uploads/2012/08/OKA9963-CATAG-RethinkingMedicines-Decision-Making-final1.pdf. Accessed 09 Jul 2020.

10. Gupta SK, Nayak RP. Off label use of medicine: perspective of physicians, patients, pharmaceutical companies and regulatory authorities. J Pharmacol Pharmacother. 2014 Apr-Jun;5(2):88-92. DOI: 10.4103/0976-500X.130046.

11. Berman AF, Melnick D. Off-label promotion, on-target sales. PLoS Med 2008;5(10):e210. DOI: 10.1371/journal.pmed.0050210. PMCID: PMC2573913; PubMed: 18959472.

12. Dresser R, Frader J. Off-label prescribing: a call for heightened professional and government oversight. J Law Med Ethics 2009;37(3):476-486, 396. DOI: 10.1111/j.1748-720X.2009.00408.x. PMCID: PMC2836889; PubMed: 19723258.

13. Committee on Drugs. Off-label use of drugs in children. Pediatrics 2014 Mar;133(3):563-567. DOI: 10.1542/peds.2013-4060.

14. Furey K, Wilkins K. Prescribing "off-label": what should a physician disclose? AMA J Ethics. 2016 Jun:18(6):587-593. DOI: 10.1001/journa lofethics.2016.18.6.ecas3-1606.

15. Carneiro AV, Costa J. Off-label prescription: practice and problems. Rev Port Cardiol 2013 Sep;32(9):681-686. DOI: 10.1016/j.repc.2013.01.006. Epub 2013 Jul 27.

16. Peckham AM, Evoy KE3, Ochs L, Covvey JR. Gabapentin for offlabel use: evidence-based or cause for concern? Subst Abuse 2018;12:1178221818801311. DOI: 10.1177/1178221818801311.

17. Kharod SC, Kang SK, Kadam SD. Off-label use of Bumetanide for brain disorders: an overview. Front Neurosci 2019 Apr;13:310. DOI: 10.3389/ fnins.2019.00310.
18. Stoehr JR, Choi JN, Colavincenzo M, et al. Off-label use of topical Minoxidil in Alopecia: a review. Am J Clin Dermatol 2019 Apr;20(2):237-250. DOI: 10.1007/s40257-018-0409-y.

19. Oliphant CS, Owens RE, Bolorunduro OB, et al. Ivabradine: a review of labeled and off-label uses. Am J Cardiovasc Drugs. 2016 Jul;16:337-347. DOI: 10.1007/s40256-016-0178-z.

20. O'Shae T. 10 surprising off-label uses for prescription medications. Accessed from https://www.pharmacytimes.com/contributor/ timothy-o-shea/2016/01/10-surprising-off-label-uses-forprescription-medications.

21. Kalil AC. Treating COVID-19-off-label drug use, compassionate use, and randomized clinical trials during pandemics. JAMA 2020 May;323(19):1897-1898. DOI: 10.1001/jama.2020.4742.

22. Shojaei A, Salari P. COVID-19 and off label use of drugs: an ethical viewpoint. Daru 2020 Dec;28(2):789-793. DOI: 10.1007/ s40199-020-00351-y. Epub 2020 May 8. PMID: 32385829; PMCID: PMC7207985.

23. Miller K. Off label drug use: what you need to know. Available from: www.webmd.com/a-to-z-guides/features/off-label-drug-use-whatyou-need-to-know\#1.

24. Lenk C, Duttge G. Ethical and legal framework and regulation for off-label use: European perspective. Ther Clin Risk Manag 2014 Jul 12;10:537-546. DOI: 10.2147/TCRM.S40232. PMID: 25050064; PMCID: PMC4103928.

25. Day R. Off-label prescribing. Aust Prescr 2013;36:182-183.

26. Field RI. The FDA's new guidance for off-label promotion is only a start. P\&T 2008 Apr;33(4):220-249.

27. Radley DC, Finkelstein SN, Stafford RS. Off-label prescribing among office-based physicians. Arch Intern Med 2006;166(9):1021-1026. DOI: 10.1001/archinte.166.9.1021.

28. Mudur G. Indian Medical Association wants off label prescribing. BMJ 2004 Apr;328(7446):974. DOI: 10.1136/bmj.328.7446.974-c.

29. Gota V, Divatia JV. Off label use of drugs: an evil or a necessity? Indian J Anaesth 2015 Dec;59(12):767-768. DOI: 10.4103/0019-5049.171555.

30. Yackey K, Stukus K, Cohen D, et al. Off-label medication prescribing patterns in pediatrics: an update. Hosp Pediatr 2019 Mar;9(3);186-193. DOI: 10.1542/hpeds.2018-0168.

31. Weda M, Hoebert J, Vervloet $M$, et al. Study on off-label use of medicinal products in the European Union. https://ec.europa.eu/health/sites/ health/files/files/documents/2017_02_28_final_study_report_on_offlabel_use_.pdf. Accessed on July 9, 2020.

32. Saiyed MM, Ong PS, Chew L. Off-label drug use in oncology: a systematic review of literature. J Clin Pharm Ther 2017;42(3):251-258. DOI: $10.1111 /$ jcpt.12507. 